\title{
O ESTADO DE SITIO, NA CONSTITUIÇÃO E NO PROJECTO DE REFORMA $\left(^{*}\right)$
}

\section{COMPETENCIA}

1. - No meu programma de ensino ha um numero: "habeas-corpus durante o estado de sitio", - que faz parte das lições sobre a theoria e o processo do habeascorpus.

Mas, ao estudal-o, tenho de considerar o instituto do estado de sitio, cujos aspectos mais importantes consignaremos nestas notas, para satisfazer á honrosa solicitação da "Revista da Faculdade"

Vejamos, pois, o estado de sitio em face da Constituição e do projecto de sua reforma, já approvado pelo parlamento, faltando-lhe apenas a votação definitiva no segundo anno.

2. - Diz a Constituição, no art. 34, n. 21:

“- Compete privativamente ao Congresso Nacional: - declarar em estado de sitio um ou mais pontos do territorio nacional, na emergencia de aggressão por forças estrangeiras, ou de commoção interna; e ap-

(*) Este estudo é a synthese das liçóes dadas nas aulas de 1914-1918, com accrescimo dos conceitos referentes á reforma constitucional e pouquissimos outros. 
provar ou suspender o sitio, que houver sido declarado pelo poder executivo, ou seus agentes responsaveis, na ausencia do Congresso"

E' o primeiro texto sobre o assumpto, não emendado pelo projecto da reforma constitucional.

Dahi decorre, evidentemente, que: - Somente á União, pelo seu Congresso, compete suspender, mediante o sitio, algumas garantias constitucionaes. Não o podem os Estados, nem outros orgams da União, porque o adverbio: "privativamente" signiflica "com exclusão de qualquer outra entidade"

Mas, si essa é a regra, como concilial-a com o art. 48, n. 15, da mesma Conștituição (tambem não emendado), que diz:

"Compete privativamente ao Presidente da Republica: - declarar por si, ou seus agentes responsaveis, o estado de sitio em qualquer ponto do territorio nacional, nos casos de aggressão estrangeira, ou grave commoção intestina (art. 6, n. 3; art. 34 , n. 21 e art. 80)"?

Em contradicção apparente a Constituição assim outorga privativamente ao Congresso e tambem privativamente ao Presidente da Republica.

A conciliação resulta, desde logo, da segunda parte daquelle primeiro texto, quando esclarece: - "asprovar ou suspender o sitio declarado pelo Poder Executivo " $n a$ ausencia do Congresso" E resulta, evidentemente, do art. $80, \S 10^{\circ}$, que mais esclarece: — " "não se achando reunido o Congresso e correndo a Patria imminente perigo exercerá essa attribuição o Poder Executivo."

Logo, é ponto pacifico que o Poder Executivo só terá competencia na "ausencia do Congresso", competencia essa que, só então, será privativa do Presidente da Repu- 
blica, excluidas outras quaesquer autoridades. A expres. são: "ou seus agentes responsaveis" é defeituosa por inutil, porque não os ha, desde que só o presidente exerce o poder executivo (art. 41).

\section{Duração do sitio decretado pelo Executivo}

3. - Surge agora uma questão mais interessante:

Até quando vigora o decreto de sitio, expedido pelo Poder Executivo na ausencia do Congresso?

A resposta logica e juridica é a de que tal decreto só vigora emquanto o Congresso não estiver reunido. Aberto o Congresso, cessa automaticamente o estado de sitio decretado pelo Executivo, porque, dahi em deante, emquanto estiver funccionando o Congresso, desapparece a competencia do Presidente da Republica, voltando a ser privativa do Congresso. Aquella existia emquanto esta não podia manifestar-se, a menos que se admittam absurdos contra a logica e a propria lingua portugueza..- Não se comprehende, realmente, que no exercicio de uma attribuição "privativa", possa o Congresso tolerar, tacitamente, a competencia cumulativa do Executivo. Portanto, reunido o Congresso, corre-lhe o dever de decretar expressamente a continuação do sitio, si o julgar necessario, assumindo assim a inteira responsabilidade da situação.

$\mathrm{Si}$, ao contrario, o Congresso nada delibera sobre o sitio decretado pelo Executivo, conclue-se, constitucional e juridicamente, que cessou o sitio e a razão que o determinára.

De outro modo seria admissivel que o Executivo, nas vesperas da reabertura do Congresso, decretasse o sitio por tempo dilatado, como exemplo, de 1 de Abril a 31 de Dezembro, para vigorar durante as sessões par- 
lamentares! Collocaria assim o Congresso na dura contingencia de renunciar á sua competencia, apesar de privativa, acceitando tacitamente o sitio, ou na contingencia de desautorar o Executivo, suspendendo expressamente o sitio.

Essa desharmonia, latente ou patente, sempre nociva, evita-se com a cessação do sitio ex-vi da abertura do parlamento. Si este entender desnecessario o sitio, nada terá a fazer, pois elle cessou ipso facto; si, porém, julgar conveniente, o decretará expressamente. E' preferivel, emfim, que o sitio cesse em virtude do silencio do Congresso, a que permaneça em virtude desse mesmo silencio, o qual, no fundo, póde parecer temor das responsabilidades, ou desidia no cumprimento de deveres. Além disso, nas Republicas, deve ser o povo, pelos seus legisladores, o competente para determinar a duração do sitio, embora podendo ouvir as informaçóes e suggestões do executivo. E' erro suppor que o poder executivo está mais em contacto com o povo.

Ao contrario, o Executivo, encerrado n'uma esphera de locomoção limitadissima, é unipessoal e acha-se mais afastado dos recantos do paiz e dos factos concretos. O Presidente da Republica, por si mesmo, pouco ouve do povo e pouco vê; a informação dos seus auxiliares, ás vezes suspeita, nem sempre suppre a observação propria, constante e larga, de que dispóem os deputados e senadores. E o patriotismo daquelle é igual ao destes.

Eis porque, em regra, é menor a duração dos sitios decretados pelo Legislativo, cuja tendencia é de restringir, emquanto que a do Executivo é de prolongar, mesmo por instincto, humano mas egoistico, de commodidade, de força e de repouso. Mas decerto não é justo, n'uma Republica liberal, sacrificar a tranquillidade do povo pelo bem-estar da autoridade. 
"No Brasil, diz Carlos Maximiliano (pag. 378), todos os presidentes, que se viram forçados a suspender as garantias constitucionaes, o fizeram por mais tempo do que o indispensavel"

4. - Essa questão da duração do sitio tem maior importancia social do que pode parecer. $\mathrm{O}$ sitio, sendo uma violencia á tranquilidade da Nação, quando motivado por commoções intestinas, deve durar o menos possivel, para significar, pela rapidez, que a ordem publica, a paz interna, a segurança e a liberdade não estão indefezas, ou não estão enfraquecidas.

Mais uma razão, portanto, para que as Constituições outorguem, como fez a nossa, ao Congresso Nacional, representante do povo, a competencia privativa para ajuizar da duração do sitio, decretando-o expressamente, ou annullando-o tacitamente quando declarado pelo Executivo.

Nem se pense "que possa ser prejudicial a cessação do sitio, desde o inicio do funccionamento do Congresso até a votação do novo sitio; porque, havendo urgencia, o Congresso poderá votal-o em algumas horas, ou em pouquissimos dias, com as dispensas de formalidades parlamentares, como já o tem feito(1); de modo que a solução de continuidade será imponderavel e sem effeitos praticos. Assim como nenhum inconveniente tem havido na suspensão do sitio nos dias de eleições.

5. - Não é novidade o que venho de dizer. Depois de haver o meu espirito assim raciocinado em face do nosso direito publico positivo, verifiquei, com desvanecimento, que na Republica do Chile tambem assim en-

(1) Si não me falha a memoria, na revolta de Julho de 1922 , o Congresso Nacional votou o estado de sitio em um só dia. 
tendeu expressamente a sua Constituição de 1833 e a sua reforma do anno passado, no texto seguinte:

- "En caso de commoción interior, la declaracion en estado de sitio corresponde al Congresso; peró si este no se hallare reunido, puede el Presidente hacerlo por un determinado tiempo.

Si a la reunion del Congresso no hubiere espirado el termino señalado, la declaracion, que ha hecho el Presidente de la Republica, se entenderá como una proposicion de ley"

Eis ahi, tambem no Chile, a cessação do sitio pelo simples facto da reabertura do Congresso e a obrigação imposta a este de se pronunciar expressamente por uma lei, cujo projecto é o acto governamental da decretação do sitio. Esse projecto pode nem ter andamento, a que equivale á sua rejeição.

5-A. - O mesmo occorre no direito constitucional da Republica Argentina, cujas disposições sobre o estado de sitio, como ensina Amancio Alcorta:

"Han sido calcadas sobre las de la Constitucion de Chile" (A. Alcorta, "Garantias Const.", 2." ed., pag. 243).

E accrescenta:

"Reunido el Congresso, el estado de sitio, declarado por el poder ejecutivo, cessa completamente, si aquelle no resuelve su continuacion. Para ello, y una vez insta- 
lado, se le comunican todos los antecedentes necessarios para que pueda formar su opinion sobre la solucion que se projecta, resolucion que viene a ser lo que la Constitucion de Chile llama una proposicion de ley" (Pags. 243 e 244).

Diz mais o illustre professor de Buenos Ayres:

"Declarado por el Poder Ejecutivo, en caso de comocion interna, cessa por su volontad antes que se reuna el Congresso; reunido este, á él corresponde examinar y resolver si ha de continuar ó si debe cessar" (Pag. 261).

Sempre a obrigação para o Congresso de exercer a sua supremacia privativa.

\section{Delegação de attribuições privativas}

6. -- Surge uma segunda questão:

? Poderá o Congresso delegar ao Executivo a decretação successiva do sitio, para vigorar durante a reunião do Congresso?

Bastam os motivos expostos para a solução negativa.

A autorização que tem o Executivo emana da Constitituição e não póde, portanto, ser ampliada por delegação de leis ordinarias. O Congresso não pode despojarse da sua competencia, durante a sua reunião, porque tal competencia é privativa. O que é privativo é indelegavel. 
7. - Esta solução já foi sustentada, com acerto, pelo Senador e jurista, Dr. João Luiz Alves, em discurso no Senado, a 10 de Novembro de 1917, assim:

- "Quer dizer, Sr. presidente, que o Congresso tira de si a responsabilidade dessa gravissima providencia, responsabilidade que a Constituição lhe attribuiu desde o momento em que elle estiver funccionando, e que só por elle deve ser exercida, porque a Constituição, no art. 34 , diz que compete privativamente ao Congresso declarar o sitio quando estiver reunido!

Quer dizer que o Congresso reconhece que sem o estado de sitio taes medidas não .podem ser tomadas, e atira para os hombros do Presidente da Republica a responsabilidade da decretação do sitio!"

Tinha razão o Senador, porque é da natureza das attribuições privativas não poderem ser delegadas.

8. - Por isso ninguem duvida que seria escandalosamente inconstitucional a delegação ao Poder Executivo, por exemplo, para:

- orçar a receita e despeza da nação;

- legislar sobre a divida publica;

- determinar o peso, valor, etc. das moedas;

- resolver definitivamente sobre tratados internacionaes;

- prorogar a adiar as sessões legislativas do Congresso; etc.

Porque? Porque são privativas essas attribuições.

Pela mesma razão não pode o Poder Executivo delegar a ninguem as suas attribuições privativas. Emfim, repetimos, o que é privativo é indelegavel. 
9. - Na America do Norte a Constituição, art. I, secção 9, n. 2, dispõe que a garantia do habeas-corpus jamais poderá ser suspensa, excepto quando a segurança publica o exigir em caso de rebellião ou de invasão. Não tendo a Const. Americana declarado privativa essa competencia, discutiu-se alli si tambem o Presidente da Republica teria igual direito em casos urgentes e imperioses. Em Abril de 1867, na guerra da Seccessão, o Presidente Lincoln autorizou o general Sccot a suspender o habeas. corpus em dadas circumstancias. Foi preso, em virtude desse sitio, um cidadão, que requereu e obteve habeascorpus. Muitas das Constituições dos Estados, lá, declaram expressamente que o poder de suspender o habeascorpus não pode ser exercido senão pelos legisladores. (Story, § 1341).

Tel était, conclue Canlier, du reste, le sentiment de Jefferson, avant son avénement à la presidence des EtatsUnis; mais une fois aux affaires, ce fut lui qui le premier sollicita du Congrès un bill de suspension de l'habeascorpus. Il ne l'obtient point. (Carlier, "La Rep. Americaine", Vol. 2, pag. 155-157, edic. de 1890).

Além dos motivos expostos, accresce, como diz Carlier: - "D'alleurs, la suspension dans les mains d'un seul homme, même dans les cas autorisés, qu'il pourrait faire surgir à plaisir, serait une arme dangereuse qui ouvrirait le chemin à la tyranie"

9-A. - No Uruguay, pela sua moderna Constituição de 1918, art. 79, n. 19, o Presidente da Republica pode tomar medidas promptas de segurança, nos casos graves e imprevistos de ataque exterior, ou commoção interna, relatando os actos e motivos, dentro de 24 horas, ao Conselho da Administração e á Assembléa Geral, ou - em sua ausencia - á Commissão Permanente. Essa attribuição, entretanto, está expressamente limitada, como o declara o texto, pelo art. 80, que diz: - "El Presidente de la Re- 
publica no podra privar a individuo alguno de su libertad personal; y en caso de exigirlo así urgentissimamente el interesse publico, se limitará al simple arresto de la persona, com obligacion de ponerla, en el perentorio termino de 24 horas, a disposicion de su Juez competente" Está limitada ainda, dil-o aquelle texto, pelo art. 152, que diz: - "Ninguno puede ser penado ni confinado sin forma de processo y sentencia legal" E, finalmente, diz aquelle mesmo texto, está limitada pelo art. 168, que reza: - "La seguridad individual no podra suspenderse sino con anuencia de la Assemblea General, o de la Comission Permanente, estando aquella en recesso, y en el caso estraordinario de traicion o conspiracion contra la Patria; y entonces, solo será para la aprehension de los delincuentes"

D'onde se vê que, mesmo em estado de sitio, não pode o cidadão ser detido si não fôr delinquente.

\section{DEFINIÇÃO E EXTENSÃO DO SITIO}

10. - Assentada assim a competencia para a decretação do estado de sitio, no direito brasileiro, vejamos a:

Definição do estado de sitio. - Etymologicamente, em sua origem, "sitiar" era o facto de cercar, assediar, rodear, por tropas, uma praça, fortaleza, cidade ou paiz.

Estado de sitio era a situação de uma praça de guerra sitiada, onde a autoridade era confiada a chefe militar; ou a situação excepcionalissima de uma cidade ou paiz, que temporariamente ficava sob o regimen militar.

Mas, tambem se tem applicado o termo para exprimir, fóra do regimen militar, a suspensão de algumas liberdades individuaes, as quaes, em verdade, se concen- 
tram na de locomoção, como veremos adeante; razão pela qual a Constituiçấo Americana, scientificamente, só suspende o habeas-corpus. Não é, portanto, a lei marcial, ou estado de guerra. (2)

No Brasil, a Const. do Imperio, art. 179, n. 35, delicadamente, não usava da expressão dura de "estado de sitio", quando permittia ao Congresso e, em sua ausencia, ao Governo, dispensar algumas formalidades garantidoras da liberdade, nos casos de rebellião ou invasão de inimigos, si assim o exigisse a segurança da patria.

$\mathrm{Na}$ Republica, porém, a Const. Federal, art. 80, empregou a expressão inconveniente (3) de "estado de sitio", definindo-o como sendo a suspensão temporaria das garantias constitucionaes.

11. - Mas, não foi, nem podia ter sido, para honra da civilisação brasileira, pensamento do legislador interromper todas as garantias, porque tal importaria na suspensão da propria Constituição e da ordem juridica, e muito menos instituir o regimen militar.

Seria, realmente, inconcebivel, além de selvagem, que o estado de sitio, fóra das praças de guerra sitiadas, interrompesse garantias, taes como:

- a igualdade dos cidadãos perante a lei; o casamento; o direitto de petição; a defesa individual, o direito de propriedade, a irretroactividade das leis, o direito adquirido, a abolição da pena de morte e outras.

(2) A expressão "estado de sitio" nasceu em França, cuja lei de 10 de julho de 1791 a mencionou, applicavel sómente ao estado de guerra. Em 1807, porém, Napoleão a ampliou ao estado de paz para as praçás de Brest e Arras não invadidas.

(3) "Inconveniente" porque, no resto do mundo, a noticia de estar o paiz em estado de sitio faz acreditar numa situaçáo gravissima, analoga a um cerco de guerra, convulsionando completamente a vida nacional, deprimindo o seu renome e o seu credito. 
12. - Quaes são então as garantias que o estado de sitio suspende?

Qual o criterio para determinal-as?

0 criterio, si não estiver expresso na Constituição, deve ser o do bom senso, da bôa fé e dos principios cardeaes da democracia estabelecidos pela propria Constituição republicana.

Portanto, não é difficil, com esse criterio, fixar como sendo, em nossa actual Constituição, susceptiveis de suspensão somente as seguintes garantias do art. 72:

$\S 8$ - o direito de reunião, que exceda á convivencia nornal;

$\S 10$. - A livre entrada e sahida do territorio nacional;

§11. - a inviolabilidade da casa do cidadão pelas autoridades competentes;

$\S 12$. - A livre manifestação do pensamento pela imprensa, ou tribuna;

§ 13. - A isenção da prisão sem culpa formada e sem flagrante;

$\S$ 14. - A fiança;

$\S$ 18. - o sigillo da correspondencia;

$\S 22$. - o habeas-corpus.

De nada mais precisará o poder publico para rapidamente conter os cidadãos transviados, ou o inimigo estrangeiro. (4)

Ora, todas essas garantias tem a sua manifestação material pela locomoção e a sua efficacia pratica pelo habeas-corpus.

13. - Logo, pode-se affirmar que bastaria suspender o habeas-corpus para que a autoridade não encontrasse

(4) A apropriação da propriedade particular, que ás vezes o poder publico tem necessidade de fazer, para defeza nacional, não se opera pelo estado de sitio, mas pelo direito de desapropriação immediata, com indemnisação posterior. 
delongas na manutenção da ordem e da defeza, como sabiamente comprehendeu a Const. Americana.

Donde se vê, dizemos entre parenthesis, que o habeascorpus só é applicavel á liberdade de locomoção, porque desta depende o exercicio de quaesquer outras garantias. Assim, sem impedir a locomoção não é possivel impedir o exercicio dos direitos de: reunião, de entrada e sahida onde quer que seja, de publicação e circulação da imprensa, do exercicio das profissões, do uso da tribuna, do recebimento, guarda e uso da correspondencia, do desenpenho dos empregos publicos, etc., etc. (5)

A confirmar, indirectamente, vemos a Constituição, no art. $80, \S 2$ (não emendado pela reforma), restringindo as faculdades do Executivo a deter pessoas, com ou sem desterro.

Ora, si o sitio só tem por fim deter pessoas, é evidente que bastaria a suppressão do habeas-corpus para que o Governo pudesse exerecer, desembaraçadamente, essa faculdade. O sitio não importa em arbitrio das autoridades, arbitrio que seria dictadura, inadmissivel mesmo em estado de sitio. Este não suspende a Constituição, senão em parte minima. (6)

14. - A reforma constitucional, que neste momento elabora o Congresso Nacional, assim comprehendeu, porque taxativamente especifica, em bem da clareza, as garantias constitucionaes que o sitio suspende, corrigindo o defeito da actual Constituição que, no art. 80, diz gene-

(5) Em outro estudo: - "O habeas-corpus, apezar de limitado á liberdade de locomoção, soccurrerá ás outras liberdades individuaes" a ser publicado no proximo numero da "Revista de Critica Judiciaria" tratamos deste assumpto.

(6) A dictadura é o governo absoluto, soberano e irresponsavel, que dispensa a existencia das leis. Em Roma nasceu das lutas civis. Dictador significa: magistrado superior e unico, temporario, cuja autoridade não tem limites. 
ricamente: "suspendendo-se as garantias" pođendo fazer suppor, erroneamente, que são todas as garantias.

Será feliz a especificação feita pela reforma? Vejamos. Diz ella:

$\S 36$. - Quando a segurança da Republica o exigir, em casos de aggressão intestina, poder-se-á declarar em estado de sitio, por tempo determinado, qualquer parte do territorio nacional, suspendendose ahi absolutamente o habeas-corpus para os detidos em virtude da declaração do sitio, assim como as garantias constantes dos $\S \S 1,3,8,10,11,12,13,14$ e 18 deste artigo, que o decreto enumerar"

Com excepção da do $\S 1 .^{\circ}$, parece-me adnnissivel a especificação das outras, desde que se queira tornar bem claro na Constituição o alcance pratico do estado de sitio, embora bastasse, como já dissemos, suspender o habeascorpus.

Com effeito, o $\$ 1 .^{\circ}$ reza: — "Ninguem pode ser obrigado a fazer, ou teixar de fazer, alguma coisa senão em virtude da lei"

Ora, não ha razão para declarar suspensa essa garantia, porque mesmo em estado de sitio, que é uma situação legal, continúa a imperar o referido principio. 0 sitio não supprime as leis; modifica pouquissimas dellas, temporariamente.

Portanto, durante o sitio, as leis obrigam, ou não obrigam, o cidadão a fazer, ou deixar de fazer, algumas coisas.

Dahi já se vê que, felizmente para honra do Brasil, não ficam suspensas pelo sitio as garantias constantes dos $\oint \S 15$ e 16 do actual art. 72 , como diremos adeante em o n. 19. 
14-A. -- E' um grande soffrimento moral e uma grave restricção á liberdade a simples declaração do estado de sitio, o qual, por si só, ainda que não produza compressão alguma, dadas a benevolencia, a longanimidade, ou a moderação do poder executor, ainda assim opprime o cidadão. Basta a possibulidade de oppressãc, para haver um soffrimento, uma ameaça, um receio permanente. Si o cidadão sabe que pode ser preso, de repente, sem flagrante, sem processo e sem pronuncia, por simples desconfiança ou intriga, ou inimizade, elle soffire continuamente, elle está comprimido, elle deixa de ser livre. E', pois, um sophisma o dizer-se que a declaração do estado de sitio, sem actos de violencia da autoridade, não tolhe as liberdades garantidas pela Constituição. Tolhe, evidentemente. Os escravos, quando muito bem tratados e estimados pelos bons senhores, continuavam a ser escravos. Além disso, é uma confissão perante o mundo do máo estado da Nação.

\section{LIMITES AO PODER EXECUTIVO}

15. - Vejamos o limite das attribuições do poder Executivo:

1) “deter as pessoas em logar não destinado aos réos de crimes communs"

Quer dizer que os detidos não sendo delinquentes julgados, merecem o respeito devido a pessoas racionaes e livres, e gosam de todas as liberdades constitucionaes, menos a de livre locomoção.

Não ha. pois, uma prisão, mas sómente uma detenção. 0 tratamento dos detidos não pode ser igual aos dos réos de crimes communs. Os detidos continuam titulares das 
suas personalidades, com direito ao conforto moral e material, porque não são condemnados, nem siquer pronunciados. Portanto, deter essas pessoas nas cadeias, ou casas destinadas ás prisões, ou em promiscuidade com os réos communs, ou apenas sob o mesmo tecto, ou no mesmo edificio, é inconstitucionalidade, punivel ex-vi do art. 80, \$ 4 da Constituição: - "As autoridades que tenham ordenado taes medidas são responsaveis pelos aluusos rmmmettidos"

Corre, pois, aos poderes publicos o dever de agazalhar do melhor modo possivel os detidos, conforme as suas posições sociaes, sem lhes causar perigos na existencia, ou excessos de soffrimento.

Eis porque no Chile a Const. consigna que a detençẫo pode ser feita na propria casa do detido. E' uma justa e humana recommendação.

\section{2) "O desterro para outros sitios do territorio nacional"}

16. - Esta medida é mais grave para a integridade da pessoa e, portanto, deve ser restricta. O desterro para certos pontos do territorio, na maioria das Nações, equivale á pena de morte, sem processo nem julgamento! Será um meio sophistico e barbaro de assassinato.

Logares ermos, insalubres, faltos de recursos, de difficil fiscalisação, jamais serão adequados ao desterro dessas pessoas ainda não julgadas criminosas. Ellas não poderiam ser promptamente acudidas, pelas autoridades superiores ou pelas familias. Será, pois, um abuso punivel o desterro em logares perigosos.

Esse afastamento nem é, no sentido juridico, um ćesterro; tamberm não é uma pena, é uma simples prevenção, que só deve ser tomada de modo a não afrontar a 
opinião publica, a civilisação e os sentimentos de humanidade e até de caridade.

$\mathrm{Ou}$, melhor, é a mesma detenção, mas em logar diverso da residencia do detido, conservando elle a sua $\mathrm{li}$ berdade e locomoção no logar para onde fôr removidio. Presume a lei que bastará esse afastamento para que c cidadão deixe de ser prejudicial. Portanto, essa detenção, impropriamente chamada "desterro", não impede que o ausente seja processado e se defenda, por seus curadores ou advogados, perante o Poder Judiciario no fôro do delicto.

A Constituição da Republica Argentina, art. 23, faculta ás pessoas desterradas, durante o sitio, sahirem do territorio nacional, si preferirem ir para paizes extrangeiros.

\section{PROCESSO, DEFEZA E JULGAMENTO DOS DETIDOS EM ESTADO DE SITIO}

17. - Chegamos á parte mais importante, a sabır:

O estado de sitio permitte conservar indefinidamente em prisão as pessoas, sem processo, sem defeza, nem julgamento?

Nãó e não. Já vimos que o estado de sitio não é o arbitrio. Não ha duvida de que o poder publico pode prender, antes de qualquer formalidade ou processo, pela necessidade de rapidez em acudir á ordem publica e de não ser embaraçado pelo habeas-corpus.

Mas, a faculdade de, rapidamente, privar da liberdade o cidadão ainda não julgado, já é muito lata para que seja ampliada a ponto de permanecer o detido, indefinidamente, na prisão, ou no desterro. 
A detenção summarissima, antes de processo e julgamento, por si só, equivale a uma denuncia do Poder Executivo contra o detido.

Denuncia de que? De delictos. Quaes? Os que estiverem preestabelecidos nas leis. Denuncia a quem? Ao Poder Judiciario, isto é, á Justiça publica nacional. A simples desconfiança, ou suspeita, a intriga, ou o boato contra alguem, não bastam para conservar presa a victima, indefinidamente sem processo, desde que a autoridade, cumprindo um dever inilludivel, apure para logo, mediante provas, a criminalidade, ou a innocencia.

E', pois, indispensavel que o detido tenha praticado ou tentado praticar um acto criminoso. No estado de sitio, justamente por ser uma situação legal, não é licito ao poder executor crear novas especies de delictos, nem dispensar o processo, com defeza e julgamento. (7) Si não ha nas leis do paiz um processo especial para esse julgamento deverá ser observado, quanto possivel, o processo commum, embora com as justas ampliações de prasos que a jurisprudencia adoptar.

18. - Ora, quaes são os delictos que justificam a detenção de pessoas em virtude do estado de sitio?

São, no direito brasileiro, os seguintes: da Patria;

- contra a independencia, integridade e dignidade - contra a Constituição da Republica e fórma de seu Governo;

- contra o livre exercicio dos poderes publicos;

- a conspiração;

- a. sedição;

e poucos mais definidos no Codigo Penal, Livro II, e outras leis.

(7) Ou, como bem articula : a Const. Argentina, art. 23: - - "Porém, durante esta suspensão, não poderá o Presidente da Republica condemnar por si, nem applicar penas." 
Somente por esses delictos o poder executor poderá deter pessoas antes de processo e condemnação.

Não se confunda, portanto, detenção ANTES de processo em virtude do sitio, com a permanencia em detenção SEM processo. São phenomenos differentes, o primeiro permittido; o segundo, não.

19. - Além dessas razões, que o bom senso acolhe, ha outra decisiva:

O estado de sitio, por sua propria natureza confirmada pela especificação feita na reforma constitucional, não suspende as garantias seguintes:

$\S 15$. - "Ninguem será sentenciado senão pela autoridade competente, em virtude de lei anterior e na forma por ella regulada"

§ 16. - "Aos accusados se assegurará na lei a mais plena defeza, com t’dos os recursos e meios essenciaes a ella, desde a nota de culpa, entregue em 24 horas ao preso e assignada pela autoridade competente, com os nomes do accusador e das testemunhas"

Estas garantias, por conseguinte, sempre estiveram e continuam de pé durante o estado de sitio, de modo que o Poder Executivo, detentor do cidadão, deve entregal-o, com os indicios e próvas, que tiver, ao Poder Judiciario, o qual não desapparece durante o sitio, afim de que este, que é o compentente para sentenciar, colha novas próvas e julgue na conformidade das leis, como diz, imperativa e claramente, o $§ 15$; tomando em consideração a defeza, que é assegurada " $a$ mais plena", com os recursos e meios essenciaes a ella, desde a nota de culpa, na forma do $\oint 16$. Deante dos $\S \oint 15$ e 
16, que o sitio não suspende, é irrecusavel a solução que acabamos de expôr. O estado de sitio não transforma o Poder Executivo em poder judiciario, nem abala os fundamentos da organisação politico-social da Republica.

Conseguintemente, por exemplo: Como impor a incommunicabilidade ao detido, além do praso da lei? Onde o. principio claro na Constituição, indispensavel para a incommunicabilidade, que fecha todas as portas á defeza dos accusados? Cumpre observar as nórmas civilisadas do nosso processo criminal, que tem sido um padrão de gloria para o Brasil. Si o detido é culpado seja condemnado ás penas legaes e cumpra a sentença, o que será preferivel a permanecer sem processo e, portanto, sem possibilidade de defesa.

Dir-se-á que no estado de sitio não será possivel, muita vez, observar os prasos curtos do processo criminal commum, por exemplo, o de 24 horas para a entrega da nota de culpa e cessação da incommunicabilidade, e o de alguns dias para terminação do summario de culpa, etc.

Sim, é verdade. Mas, é banal que, dado o accumulo de serviço, evidenciada a força maior, o poder judiciario, deante das impossibilidades como essa, tem competencia para attenuar os rigores dos prasos, e a jurisprudencia. em face dos conflictos de leis e de interesses tão elevados, suppre pela hermeneutica os casos omissos nas leis insufficientes.

No Uruguay, por exemplo, como vimos em o n. 9-A, nem essa hermeneutica é tolerada, porque o art. 80 da Const., quando autorisa o Presidente da Republica a deter pessoas em casos urgentissimos de interesse publico, impõe-lhe, entretanto, a "obligacion de ponenla, en el perentorio termino de 24 horas, a disposicion de su Juez legal" E' um criterio verdadeiramente democratico, porque só o Judiciario é competente para processar e julgar, desde o 
momento da prisão, ainda que motivada pelo estado de sitio, que não é lei marcial em virtude da qual os tribunaes militares processam e julgam as infracções das leis de guerra, occorridas nas zonas ou campos de batalha.

Em summa, no direito brasileiro, o estado de sitio apenas autoriza o Executivo a deter pessoas antes de processo e fóra de flagrante, para entregal-as immediatamente ao Poder Judiciario. Nada mais. Si outra tem sido a hermeneutica, está errada, em minha desvaliosa opinião, data venia.

De outro modo, os sediciosos, que fogem após a pratica de crimes e violencias materiaes, ficarião em melhor situação, porque seriam processados, defendidos e julgados perante o Poder Judiciario, como aconteceu com os da revolta de 1924; ao passo que os sediciosos ou conspiradores, que não chegarem a praticar actos materiaes, detidos em razão do estado de sitio, ficariam sem processo e julgamento. Ora, essa desegualdade, tratando-se dos mesmos delictos, é injustificavel, pois não é natural, nem presumivel, que os ultimos sejam mais perigosos á ordem publica do que os primeiros.

\section{HABEAS-CORPUS AOS DETIDOS PELO SITIO}

20. - Em vista do que acabamos de expor, qual será o remedio para o caso de ser o detido conservado em prisão indefinidamente, sem processo e julgamento?

E' o habeas-corpus, incontestavelmente, porque a violação dos $\$ \delta 15$ e 16 do art. 72 da Const., pela demora injustificavel do processo e julgamento, transforma em abuso de poder a prisão, que inicialmente fôra legal.

Mas, a isto poder-se-á indoutamente, objectar que, se vingar a reforma constitucional, a emenda, que figura como $\$ 36$, réza: "Suspendendo-se ahi ABSOLL' TAMENTE o habeas-corpus para os detidos em virtude do estado de sitio" 
Até onde irá a força da palavra: "Absoluta mente"? Não pode ir ao infinito, porque daria logar á dictadura, que, em caso algum, a Constituição permittiria. Para mostrar que o "absolutamente" não é absoluto, vamos figurar um exemplo, assim: Si a autoridade impedir ao dețido de casar-se, estando algum dos nubentes em imminente perigo de vida (Cod. Civil, art. 199, n. 111), e prohibil-o de receber na prisão o outro contrahente, as testemunhas e o juiz de casamentos, ou de sahir da prisão para ir á casa em que estiver o nubente em risco de vida, emfim, prohibindo a locomoção necessaria ao acto; ou se impedir ao detido de fazer testamento, ou de vender ou comprar bens immoveis, ou de fazer procurações, locomovendo-se para isso ou pondo-se em contacto com o tabellião, testemunhas, etc., ficará o detido privado do exercicio desses direitos?! De modo algum, pois o estado de sitio não lhe retirou os direitos civis. Logo, caberá o habeas-corpus para obrigar a autoridade a facilitar ao detido tudo quanto seja necessario, inclusivé a sua locomoção e a sua communicabilidade, para o uso daquelles direitos. Si, em virtude do sitio, forem detidos deputados, senadores, ministros do Supremo Tribunal, caberá o habeas-corpus.

Eis ahi casos irrecusaveis (e como esses ha outros) em que, a despeito do "absolutamente", cabe habeas-corpus aos detidos. Aquelle adverbio é inhabil deante da realidade das coisas. Não annulla as garantias dos $\oint \oint$ 15 e 16 e outros direitos, que o sitio não suspende.

E para assim o decidir ahi estão os tribunaes, principalmente, o Supremo Tribunal Federal, interprete da Constituição. Nem outra é a missão salvadora do Poder Judiciario.

Este continúa, durante o sitio, a ser orgam da soberania nacional, com a mesma independencia e harmonia, que o sitio não supprime, expressas na Constituição, art. 15. 
Não seria, pois, acertada a jurisprudencia que recuzasse habeas-corpus sob o unico pretexto de estar o cidadão detido em virtude do estado de sitio. Não bastaria, para essa detenção, a suspeita, ou a possibilidade, de que o preso venha a praticar violações da ordem publica. Para prevenir, quanto possivel, essa possibilidade ha a vigilancia e os cuidados da policia.

A these verdadeira, portanto, é esta: Em estado de sitio podem ser detidos, antes de processo, os delinquentes contra a segurança e integridade da Nação.

\section{RESPONSABILIDADES}

21. - Qualquer mandato está subordinado á prestação de contas do mandatario ao mandante. E' um dever legal e natural do mandatario, além de ser do seu interesse para se aliviar de responsabilidades moraes.

Ora, o Poder Executivo decreta o estado de sitio por mandato da Nação, representado pelo Congresso.

Eis porque, mui prudentemente, a Constituição, no art. $80, \S 3$, mantido na reforma, estatúe:

- "Logo que se reunir o Congresso, o Presidente da Republica lhe relatará, motivando-as, as medidas de excepção que houverem sido tomadas.

As autoridades que tenham ordenado taes medidas são responsaveis pelos abusos commettidos"

Antes de tudo, cumpre salientar a expressão ahi usada: "logo que", para exprimir a urgencia com que o relato do Presidente deve ser enviado ao Congresso. De facto, "logo que" significa: "no momento em que", "sem perda de um instante" Qualquer tardança, embora tolera- 
vel si não fôr exagerada, será entretanto contraria ao espirito e á lettra da Constituição, pois nada impede ao Executivo de cumprir exacta e elegantemente a lei.

E' mesmo do seu interesse fazel-o para livrar-se de suspeitas ou accusações muitas vezes injustas, que, entretanto, impressionam o espirito publico e apparentam visos de verdade em occasióes, como essa, de paixões politicas. Cada prisão acarreta para o Executivo centenas de inimigos e de rancores. 0 relatorio, motivado, mostra pelo menos a boa fé e o escrupulo com que foi cumprida a lei em been da ordem e da salvação publica. A omissão, portanto, será prova indirecta do contrario.

Esse relatorio não é uma simples noticia em termos geraes, nas mensagens inauguraes ou especiaes enviadas ao Congresso. Deve ser uma exposição minuciosa e "motivada, das medidas de excepção que houverem sido tomadas"

Estas palavras do texto, bem claras, dizem, a não deixar duvida, que devem ser relatadas todas as medidas, principalmente as prisões effectuadas, com os nomes, motivos e logares (pois é a unica attribuição do Executivo); afim de que o Congresso, que representa o povo, ajuize acerca da execução do mandato conferido ao Executivo, bem como da situação das liberdades publioas e dos abusos commetidos.

Ensina o eminente constitucionalista e membro da constituinte, João Barbalho (pag. 125) : - "Esse relatorio, \& Camara, si assim entender, poderá tomar por base, não para o immediato julgamento do Presidente, o que seria um contrasenso, mas para iniciação do processo de responsabilidade (impeachment) si houver fundamento para isso; o que pode fazer mesmo independentemente desse documento"

Quaes são os "abusos commettidos"?

São os actos exorbitantes das leis; o que prova, ainda uma vez, que o sitio é um estado legal e não dictadura, 
e que as autoridades não dispõem da sua vontade discrecionaria, mas devem agir dentro das leis, e que, finalmente, as prisões devern basear-se na infracção, ou tentativa de infracção de leis, por parte dos detidos, e nunca em suspeitas, desconfianças, como dizemos em os ns. 17 a 20 . Não basta a simples affirmação sem próvas, ou indicios vehementes e legaes, de que o detido é perigoso á ordem publica.

De modo que são áusos de autoridade, por exemplo:

- prender sem motivos legaes, isio é, sem que os presos tenham violado ou tentado violar as leis, como dizernos em os ns. 17 e 18;

- conservar em prisão sem processo, defeza e julgamento, violando, assim os $\oint \oint 15$ e 16 do art. 72 da Constituição, como dizemos em o n. 19;

- inflingir castigos, soffrimentos, ou desterros para logares perigosos, podendo causar o sacrificio da vida e da saude dos detidos;

- tratar os detidos como réos de crimes communs, ou condemnados;

- attentar contra as liberdades e direitos não suspensos pelo sitio;

- não cumprir os habeas-corpus decretados pelo Poder Judiciario;

- e outras infracções de garantias e de leis não interrompidas pelo sitio.

$O$ processo de responsabilidade dos agentes das autoridades, promovido ex-officio, ou pelas victimas, será o que estiver traçado nas leis, assumpto que não desenvolvemos aqui por exceder aos limites deste ligeiro estudo.

22. - O relatorio motivado e minucioso ao Congresso Nacional, além dos fins que acabamos de expor, tem o de proporcionar-lhe os meios de cumprir o dever de "approvar ou suspender" o sitio, na forma do art. 34, n. 21 . 
Isso significa, entretanto e sómente, que a approvação do sitio importa no reconhecimento de ter sido elle necessario nos termos da Constituição, isto é, de ter havido aggressão estrangeira, ou commoção intestina, que mereciam a medida excepcional e gravissima do estado de sitio e que, portanto, o Governo agiu bem.

A approvação, pois, como diz João Barbalho: "não visa o exame e approvação dos varios actos pratica. dos pelas autoridades durante o sitio"

Taes actos podem ser illegaes e exorbitantes, embora seja legal e cabivel o estado de sitio. Neste caso, a approvação do sitio não importa em approvação de actos illegaes, cujos responsaveis devem ser processados pelo poder competente, ex-officio, ou mediante provocação dos interessados, afim de serem punidos como fôr de lei. E' o que resulta do $\S 4$ do art. 80: - "As autoridades que tenham ordenado taes medidas são responsaveis pelos âbusos commettidos"; o que (mais uma vez o dizemos) prova que o estado de sitio ê uma situaçáo legal, durante a qual a lei continúa a imperar.

23. - Finalmente, para terminar estas notas, q!e apenas visam os pontos principaes da materia, no direito brasileiro, observaremos que a nossa Constituição (neste particular não emendada pela reforma) é prolixa, porque contêm, sem methodo, os textos dos arts. 34, n. 21, 48, n. 15 , e art. 80 e seus $\oint \oint$, que melhor ficariam enfeixados num só dizendo:

- Art. 34. - Compete privativamente ao Congresso Nacional:

n. 21. - suspender num ou mais pontos do territorio nacional, por tempo determinado, as garantias constantes dos $\$ \oint 3,8,10,11,12,13,14,18$ e 22 do art. 72 , nos casos de aggressão estrangeira, ou commoção interna; exercendo essa attribuição, durante a ausencia do 
Congresso, o Presidente da Republica, o qual se limitará a:

$\left.1 .^{\circ}\right)$ deter pessoas em logares não destinados aos réos de crimes communs; e $2 .^{\circ}$ ) a desterral-as para outros pontos do territorio nacional.

$\S 1 .^{\circ}-$ Logo que funccionar regularmente o Congresso cessarão os effeitos do sitio decretado pelo Presidente da Republica, o qual relatará ao Congresso, motivando-as, as medidas de excepção que houverem sido tomadas.

$\S 2 .^{\circ}-$ As autoridades que tenham ordenado taes medidas são responsaveis pelos abusos commettidos.

Estão ahi contidos, em seu verdadeiro pensamento, todos os principios actuaes, inclusivé os da reforma já votada em primeiro turno. Salvo melhor juizo.

S. Paulo, Janeiro, 1926.

Dr. J. M. de Azevedo Marques.

(Professor aposentado da Faculdade de Direito de S. Paulo). 